\title{
ANTONIO LÓPEZ ORTEGA: HACIA EL CUENTO LÍRICO
}

\author{
POR \\ Carlos Leáñez Aristimuño \\ Universidad Simón Bolívar
}

\section{PResentación}

Antonio López Ortega inicia sus incursiones en la escritura desde la escuela. Durante sus años de estudio en la Universidad Simón Bolívar, participa en el taller literario dirigido por Juan Calzadilla y publica varios cuentos en revistas auspiciadas por esa institución. "Larvarios", inserto en un volumen colectivo titulado Cuerpo plural (1978), constituye su primer conjunto de cuentos publicado. Encontramos allí veinte microrrelatos que desarrollan anécdotas claras, oscilantes entre lo fantástico y lo místico, vertidas en un lenguaje ágil y preciso. "Armar los cuerpos", incluido en un volumen de la colección Voces nuevas (1982), comprende diez cuentos de mayor extensión, escritos entre 1977 y $1978,{ }^{2}$ donde la comprensión de la historia tiende a complicarse debido a la experimentación. Los resultados son muy irregulares. En Cartas de Relación (1982), primer volumen individual del autor, encontramos un lenguaje acompasado, de adjetivación escrupulosa y altamente metafórico, que desdibuja un tanto la secuencia narrativa. Aquí el recuerdo desentraña - a través de cartas breves, reunidas en bloques separados de acuerdo al destinatario- vínculos con figuras como el padre, la madre, la mujer, el amigo. No se trata de cuentos, ni de una novela, aunque utiliza elementos de los dos: las cartas tienden a retomar episodios puntuales, el volumen tiende a construir un mundo. Calendario (1990) es un texto hermético que confirma el progresivo alejamiento de López Ortega de sus comienzos como narrador. En este libro, que escapa a los encasillamientos genéricos, el discurso se fragmenta en forma de cortas anotaciones diarias, se teje entre la poesía y la reflexión, mientras que la historia no está lejos de desaparecer. Naturalezas menores (1991) configura una vuelta a la anécdota clara que encontramos en "Larvarios", una negación de los afanes experimentales de "Armar los cuerpos" y una retoma de los recursos utilizados en Cartas de Relación, pero sin entorpecer, en este caso, el curso de la historia. ${ }^{3}$

\footnotetext{
${ }^{1}$ Parte de este estudio fue presentada en el "XVIII Simposio de Docentes e Investigadores de la Literatura Venezolana", celebrado en Caracas el 26 y 28 de noviembre de 1992.

${ }^{2}$ Durante ese período el autor era miembro del taller de narrativa auspiciado por el Centro de Estudios Latinoamericanos Rómulo Gallegos, dirigido en ese entonces, sucesivamente, por Antonio Márquez Salas y Oswaldo Trejo.

${ }^{3}$ Este párrafo surge de una ficha que realicé en el seno del equipo de investigación de la Universidad Simón Bolívar que seleccionó una muestra del cuento venezolano de los últimos treinta años.
} 
Naturalezas menores ocupará nuestra atención a lo largo del trabajo. Este libro consta de tres secciones. En dos de ellas se mezclan dos universos temáticos: la niñez y adolescencia, por un lado; la temprana edad adulta, por el otro. La otra sección es, como lo señala su nombre, un diario de viaje. Utilizando un pequeño corpus representativo de técnicas y estructuras, perseguimos llegar a una caracterización de cómo López Ortega aborda el cuento referido al mundo de la infancia y la adolescencia en la primera sección de su libro más reciente.

\section{El CUENTO: LA DEFINICIÓN IMPOSIBLE}

Meneses sostiene que "el cuento es una relación corta, cerrada sobre sí misma, en la cual se ofrece una circunstancia y su término, un problema y su solución (Meneses 1966: 5). Pero la definición anterior se nos antoja insuficiente. ¿Por qué? Una "circunstancia y su término" es sólo un cambio de estado. ¿No es eso un antes y un después, lo irrenunciable en cualquier mensaje narrativo? Van Dijk, al tratar la "narración natural" (Van Dijk 1989: 154), es decir, aquélla que utilizamos cotidianamente sin ningún fin artístico, indica que su esencia gravita en torno al suceso (Van Dijk 1989: 156), el cual se descompone en una causa y su reacción: ${ }^{4}$ Meneses y Van Dijk están hablando de lo mismo. Estamos seguros ahora de la raíz de nuestra insatisfacción: Meneses no ha definido el cuento, ha más bien explicitado el núcleo de todo mensaje narrativo. Ahora bien, Friedman y Wright, en 1989, al reflexionar sobre la definición del género, no van mucho más lejos. Sostiene el primero que a lo máximo que se puede llegar sin caer en excepciones es a "narrative fiction in prose which is short" (Friedman 1989: 15). Así, se deja afuera "a range of possibilities regarding the size of the action, the manner of representation and the nature of the end effect ... [así como los rasgos que] are accidental and historically conditioned" (Friedman 1989: 30). El segundo no va más lejos, ratifica el concepto básico de Friedman (Wright 1989: 50 ), e indica que "a definition of the short story cannot say much about the manner of its telling ... subject matter ... particular effect ... techniques" (Wright 1989: 52).

Constatamos entonces que una definición aplicable a todos los cuentos no nos dice mucho acerca de su esencia narrativa: la manipulación de un suceso central. Entendemos por qué: ella suele ser diferente de autor a autor, de época a época, de cuento a cuento. Quizás por ello optó Meneses por quedarse en un terreno neutro, en una caracterización aplicable a todo mensaje narrativo. Quizás sólo sea posible definir el cuento de manera inductiva y en relacion a un corpus preciso.

Precisemos, antes que todo, algunos puntos obvios: los textos de nuestro corpus están todos escritos en prosa y son cortos. Podemos admitir también que son textos de ficción: un autor real se ha desdoblado en un narrador. La pregunta clave es: ¿manipulan un suceso central? En caso afirmativo, su manera específica de hacerlo constituirá su forma particular de encarnar al cuento, la cual es la que nos interesa para rebasar la definicion básica y establecer una caracterización más precisa, aunque casuística. Para lograrla, pasemos al análisis de nuestro corpus.

\footnotetext{
${ }^{4}$ Van Dijk las llama complicación y resolución. Preferimos llamarlas causa y reacción, ya que nos parecen términos más neutros. En efecto, la palabra complicación puede estar asociada a algo negativo, mientras que con resolución ocurre lo contrario.
} 


\section{EL CORPUS}

"La nuez" (39-40) nos relata cómo una niña, con la complicidad de su madre, se aparecía en las fiestas infantiles usando una falda larga a objeto de cubrir con ella lo que caía de las piñatas, vedando así a los otros el acceso al tesoro. Hasta aquí se desarrolla un bloque del texto que llamaremos los antecedentes. Luego se nos cuenta la tarde en que la niña insiste en su comportamiento y el héroe se decide a introducir el brazo bajo la falda. Allí tiene lugar el bloque que llamaremos suceso central. Más tarde se pasa a un tercer bloque —el bloque de cierre - que prepara el final antes de culminar con una frase del héroe que constituye el punto de cierre: "Es sólo un caramelo - atiné a decir-es sólo un caramelo". Estos tres bloques los hallamos en casi todos los cuentos, sin embargo no están siempre nítidamente separados. Poco importa. Sus funciones siempre las encontramos, aunque estén subsumidas en otros bloques. ${ }^{6}$

Detengámonos en cada uno de los tres bloques detectados, comunes a casi todo nuestro corpus. En los antecedentes hallamos factores muy variados cuya misión parece ser la

${ }^{5}$ Indicaremos las páginas de los cuentos sólo al presentar sus títulos al comienzo de cada análisis. Igualmente, para facilitar la comprensión del estudio, citaremos en la nota de pie de página el texto integral del cuento en cuestión. He aquí el texto de "La nuez":

Mariflor llegaba a las piñatas con una falda larga y, generalmente, floreada. "Un homenaje a su nombre" - decía sonriente la madre mientras probaba un suspiro. Pícara y caprichosa, Mariflor agitaba la cabeza de un lado al otro para que sus rizos dorados bailaran y le cubrieran de vez en cuando unos ojos abiertos como pozos negros.

Nunca pudimos negar su gracia, su manera peculiar de hacer las cosas. En la piscina era una aventajada nadadora y en las competencias de la escuela no había quien le ganara. Trepaba los árboles con los pies desnudos y hasta era capaz de saltar desde alturas que nos avergonzaban. Había en ella como una pulsión varonil que constantemente nos retaba.

Lo de la falda larga tenía sus motivos. Mariflor esperaba con ansias que el niño de turno le abriera un boquete a la piñata y, una vez que caían al suelo las golosinas, se abalanzaba sobre el motín abriendo su falda como un gran abaníco y cubriendo buena parte de los regalos. Por supuesto que nadie se atrevía a aventurar una mano bajo la falda. Como pequeños montículos entrelazados a sus piernas o bajo las propias asentaderas, imaginábamos caramelos de frutas, caballitos de plástico, galletas de chocolate, pitos estridentes, pelotas multicolores, chupetas, serpentina y papelillo.

Los niños comenzaban a rumiar el evidente ventajismo de la maniobra e incluso las madres confundidas más allá con gelatinas, tequeños y manteles de papel - reprobaban la actitud sin hacerla manifiesta, pues la madre de Mariflor - nuevamente con un suspiro en la boca- cultivaba con sonoras carcajadas una no muy oculta complicidad.

No podía decir si la contramaniobra fue planeada o fruto espontáneo de la voluntad. Debo, sí, admitir que la vimos llegar nuevamente con su falda floreada, que se colocó estratégicamente al lado del que en ese momento le amputaba una pierna a Superman y que, como de costumbre, se abalanzó sobre el tesoro con su enorme falda abierta.

Mariflor no supo cómo reaccionar cuando sintió que mis manos rozaban sus muslos: había aventurado velozmente mi brazo bajo la falda hasta dar con algo que parecía una nuez forrada en tela. Boquiabierta, sin saber qué podía significar el contacto con su cuerpo, me derramó sus ojos absortos como esperando una respuesta. "Es sólo un caramelo - atiné a decir-, es sólo un caramelo".

${ }^{6}$ En "Los labios de Laura", por ejemplo, el suceso central se hunde en el bloque que llamamos antecedentes, y en "De rodillas" el suceso y el tercer bloque se confunden. 
preparación de un terreno que justifique el advenimiento del suceso central. Algunos de estos factores funcionan como indicios - más o menos discernibles — de lo que vendrá; otros como marco, es decir, proporcionando las circunstancias espacio-temporales en las que se inscriben los indicios; y otros, en fin, como ambos. Estas funciones se revisten de formas muy diversas. Así, en nuestro cuento, encontramos adjetivos - "pícara y caprichosa"; hechos recurrentes - "trepaba los árboles con los pies desnudos"; sucesos recurrentes - "caían al suelo las golosinas, se abalanzaba sobre el motín abriendo su falda".

Pasemos ahora al suceso central. Para entenderlo, volvamos por un momento a las definiciones básicas del género cuento. Todas señalan que es corto, Wright incluso propone un límite máximo: "never much longer than 'Heart of Darkness"" (Wright 1989: 50). Lo anterior tiene una causa profunda: el cuento posee sólo un suceso central, que coadyuva decisivamente a lo que Poe llamó "unity of effect or impression" (Poe 1976: 46). ${ }^{7}$ Aquí late el corazón narrativo del cuento, no en los antecedentes. Entendámonos: éstos, como acabamos de ver, contienen elementos que, individualmente considerados, son narrativos, pero que en la globalidad tienen una función distinta: crear un espacio de sentido -rol más bien estático- en el que se inscribirán las acciones clave, lo propiamente narrativo, el suceso central. Así, mucho más que generar un antes y un después, los preparan, posibilitan su inserción. Esta subordinación de los antecedentes al suceso central contribuye ciertamente a dar un perfil narrativo a los textos, mas la extensión netamente mayor de aquellos tiende - en "La nuez" y en todos los relatos- a involucrar a los textos más en la creación de una atmósfera que en el despliegue de una cadena de acontecimientos: los avecina a la poesía. He aquí quizás una de las causas de la oscilación entre lo narrativo y lo lírico de la cuentística de López Ortega.

Pero volvamos al cuento que nos ocupa. Una vez que los antecedentes han consolidado "el evidente ventajismo" de la maniobra de Mariflor, nos hallamos listos para el suceso central. La chica crea la causa al persistir en su hábito: "se abalanzó sobre el tesoro con su enorme falda abierta". El héroe genera la reacción al introducir su "brazo bajo la falda hasta dar con algo que parecía una nuez forrada en tela". Todo resalta con respecto al bloque anterior por el uso de la frecuencia singulativa ${ }^{8}$ que hace de cada hecho algo único, que contrasta con la frecuencia iterativa ${ }^{9}$ precedente; así como por la clara preeminencia de la sucesión de acciones — "la vimos llegar ... se colocó ... se abalanzó ... no supo ... sintió ...- acompañadas del marco mínimo necesario para su cabal comprensión", "estratégicamente al lado del ... sobre el tesoro con su enorme falda abierta ... bajo la falda": es el momento máximo del contar.

\footnotetext{
${ }^{7}$ En casi todos los cuentos hallamos varios sucesos, pero sólo uno es central. De tratarse de un texto narrativo que no posea un solo suceso central, sino varios, estaremos entrando a otros formatos: la noveleta, la novela. Se perderá además la mencionada unidad de efecto.

${ }^{8}$ Genette la define como aquella en la que se cuenta una sola vez lo que ocurrió una sola vez (Genette 1972: 146). Es la frecuencia narrativa por excelencia: los hechos singulares se van encadenando y estructuran el relato.

${ }^{9}$ Genette la define como aquella que cuenta una vez en el relato aquello que ocurre cualquier cantidad de veces en la historia (Genette 1972: 147). Indica que suele tener un rol más descriptivo que propiamente narrativo.
} 
Si bien ya llegamos al final del suceso, todavía no hemos arribado al punto de cierre. En efecto, éstos no coinciden: tras "parecía una nuez forrada en tela", el relato continúa. ¿Por qué, si el suceso central ya transcurrió, se tiene todavía la sensación de que queda algo pendiente? Porque no ha concluido el proceso de acabado. Este no persigue contar un suceso completo, sino crear las circunstancias gracias a las cuales se tiene la sensación de que "nothing of importance has been omitted from a work" (Torgovnick 1981:6). ${ }^{10}$ En el caso de "La nuez" - y, como veremos, en prácticamente todo nuestro corpus-el acabado comienza con los antecedentes que dan pie al suceso central, continúa con éste que, a su vez, abre el terreno al bloque de cierre, el cual abre paso y contiene en su final el elemento con el que concluye el relato, así como el proceso que describimos. En ese elemento -el punto de cierre - todo converge, cobra sentido y se estabiliza; comienza para el lector una ensoñación retrospectiva que ha de llevarlo, difusa o claramente, a cierta significación. Así, donde concluye el acabado se abre el sentido.

¿Cómo funciona el punto de cierre, en "La nuez"? Se trata de una simple frase repetida: "Es sólo un caramelo - atiné a decir - es sólo un caramelo". Esta frase, ubicada justo al final del texto, se carga al máximo de todo lo precedente — de los "rizos dorados", de "su gracia, su manera particular de hacer las cosas", del mundo "bajo las propias asentaderas", del "tesoro", de Mariflor boquiabierta-y reserva para lo último la revelación equívoca: ¿es el caramelo el brazo que se ofrece, es la nuez que se oculta, es un simple dulce, es todo una metáfora del deseo? Se abre la ensoñación.

Antes de continuar debemos detenernos a objeto de realizar algunas precisiones terminológicas. En su libro Figures III, estudia Genette las relaciones existentes entre la historia (histoire), el relato (récit) y la narración (narration). Según él, la primera constituye "le signifié ou contenu narratif (même si ce contenu se trouve être, en l'ocurrence, d'une faible intensité dramatique ou teneur événementielle)" (Genette 1972: 7). La historia es pues lo contado. El relato viene a ser "le signifiant, énoncé, discours ou texte narratif luimême" (Genette 1972: 72), es decir, el texto. Por último, la narración es "l'acte narratif producteur et, par extension, l'ensemble de la situation réelle ou fictive dans laquelle il prend place" (Genette 1972: 72).

Dedica Genette uno de los capítulos al estudio de la voz (voix), es decir, al estudio de las relaciones entre narración y relato, así como entre narración e historia. Son estas últimas las que más nos interesarán. Es la voz la que establece el sistema de vasos comunicantes entre el héroe - "erzähltes ich (je narré)" (Genette 1972: 259)- que se halla en el tiempo de la historia y el narrador - "erzählendes ich (Je narrant)" (Genette 1972: 259) - que se halla en el tiempo de la narración. Estos vasos comunicantes, como veremos, constituyen uno de los aspectos más interesantes de nuestro corpus.

En lo sucesivo utilizaremos estos términos de manera unívoca para evitar confusiones.

"Mayra siempre sacaba la lengua", la estiraba, la escurría, y el héroe y sus amigos se la disputaban "en las tribunas del recreo", en "los oscuros camerinos del gimnasio". Así,

\footnotetext{
${ }^{10}$ Para calibrar si lo recién señalado se ha logrado, considera Torgovnick que deben tenerse en cuenta "the honesty and the appropriateness of the ending's relationship to beginning and middle" (Torgovnick 1981: 6), de allí que sostendremos que el acabado es un proceso que apunta al final, pero lo prepara imbricando elementos desde las primeras líneas.
} 
en una frecuencia iterativa que denota un contacto diario, transcurren los tres primeros párrafos de "La lengua" (13-14), " que nos llenan de indicios de vida y sensualidad. Siguen unos hechos cuya condición singulativa revela un alejamiento, el fin de una edad en donde ver a Mayra era cotidiano; son encuentros esporádicos cuya evocación requiere de un especial esfuerzo de la memoria y que poco significan: "Recordamos, sí, una fiesta de fin de año en la que su madre preparó galletas saladas con jamón y distribuyó cervezas. Recordamos, sí ...". ${ }^{12}$ Culminan de esta manera los extensos antecedentes y, de súbito, se abre un tono por completo distinto: "viajando en época de lluvia por la carretera de tierra que une Carenero con Chuspa, un rústico conducido por el novio hunde las ruedas en un charco de barro y cae del lado derecho expulsando a Mayra por la ventanilla y aplastándola contra el suelo". Encontramos aquí múltiples elementos que hacen resaltar el suceso central: la ya señalada frecuencia singulativa que vuelve a cada hecho algo único y que contrasta con los antecedentes más bien iterativos; el presente histórico que da inmediatez y nitidez, que presenta, más que contar; las acciones que se suceden una tras otra, con el mínimo marco necesario para su cabal comprensión. He aquí un bloque netamente narrativo en total contraste con el mundo de los antecedentes.

Mas no ha culminado el proceso de acabado. El narrador desea darle contundencia al punto de cierre y lo logra desplegando varios recursos. Por una parte, nos da un primer plano de lo que antes no podíamos ver; por la otra, congela la imagen en el recuerdo, ya que perdura "desde entonces" y a pesar de los esfuerzos por borrarla. Además, el simple

${ }^{11}$ A continuación el texto de "La lengua":

Mayra siempre sacaba la lengua. La estiraba hasta casi rozar la nariz. Primero la punta temerosa que ensalivaba los labios y luego el cuerpo robusto que se arqueaba dejando entrever los ríos azules de la base.

Así la veíamos llegar todas las mañanas: el lunar invariable del pómulo derecho, el rizo que constantemente se recogía detrás de la oreja, lo resoplones que daba a cada paso ... Entraba siempre tarde al salón de clases, saludaba al profesor de turno con una media sonrisa y dejaba caer sobre el tercer pupitre de la primera fila el bulto de libros que apilaba contra el pecho. Desde el flanco derecho del salón comenzaríamos a buscarle la mirada: Gustavo escrutando por sobre los lentes, Eduardo mostrando el sacapuntas de acero inoxidable, Carlos completando los apuntes con dilatada caligrafía. Mayra se volvía de golpe y, entornándole los ojos al primer afortunado, dejaba escurrir la lengua.

Signo creciente y perturbador de los días, nos disputábamos su lengua en las tribunas del recreo, nos llevábamos su lengua a los oscuros camerinos del gimnasio.

Poco, en verdad, supimos después.

Recordamos, sí, una fiesta de fin de año en la que su madre - hecha anicos tras un divorciopreparó galletas saladas con jamón y distribuyó cervezas. Recordamos, sí, un encuentro fortuito en el cafetín de una universidad donde nos entretuvo con una sonrisa lozana y ecuaciones infinitesimales. Nos la devolvió abruptamente un obituario: viajando en época de lluvia por la carretera de tierra que une a Carenero con Chuspa, un rústico conducido por el novio hunde las ruedas en un charco de barro y cae del lado derecho expulsando a Mayra por la ventanilla y aplastándola contra el suelo. Desde entonces, quisiéramos creer que Mayra aún nos pertenece; desde entonces, quisiéramos borrar esa última imagen a la que algunos tuvimos acceso: la lengua amoratada entre los dientes, la lengua cercenada bajo el impacto de la carrocería.

${ }^{12}$ Las cursivas en las citas de Naturaleza Menores hechas en el texto principal son siempre nuestras salvo que se indique lo contrario. 
hecho de disponer la imagen en las palabras finales le permite aprovechar al máximo el efecto acumulativo. Así, la "lengua cercenada bajo el impacto de la carrocería" elimina a la lengua vibrante de los primeros párrafos, no admite siquiera azarosos encuentros esporádicos ulteriores: parece apuntar hacia un abandono definitivo de la niñez y la adolescencia, de un mundo lleno de vida, inolvidable y clausurado, hacia un estado de destierro. Así, como vemos, al cerrarse el relato, se abre el significado.

En "Los labios de Laura" (11-12) $)^{13}$ hallamos un cuento cuyo suceso central no se dibuja de manera nítida, como en los dos anteriores. Sin embargo, debemos encontrarlo para afirmar que estamos ante un cuento. Examinemos entonces el texto. En primer lugar, distinguimos un bloque de hechos donde "Laura se escondía para enseñarnos a besar ... Laura llamaba ... proyectaba sus labios hasta tocar los nuestros ...". Luego encontramos otro bloque donde los muchachos terminaban "siempre arrojando las sillas ... construyendo castillos submarinos ..." y Reynaldo el portero los "sacaba de la piscina" tirando de sus orejas. Así desciframos una causa —el aprendizaje del beso-y una reacción —la excitación generalizada de los muchachos. Sí hallamos entonces un suceso central, pero observamos que se encuentra diluido y mezclado con los factores que en los otros textos constituían los antecedentes. Esta inconsistencia del nervio principal de los acontecimientos genera textos que nos impregnan más en base a una atmósfera que en base a acciones, lo cual nos coloca de nuevo ante un alejamiento de lo estrictamente narrativo.

Ahora bien, el proceso de acabado no culmina con Reynaldo que saca a los muchachos de la piscina. De haber sido así, el lector simplemente terminaría sonriendo ante la travesura de los niños excitados tras su perturbador aprendizaje. Pero el narrador desea otro efecto final y propone como punto de cierre una suposición: Reynaldo "aún debe estar buscando a la escurridiza Laura cada vez que se topa con una mata de cayenas". Se abre entonces la búsqueda de sentido del lector y pensamos que esa suposición puede indicar sutilmente que, hasta el momento de la narración, la excitación causada por Laura perdura. Claro, Reynaldo aún no la ha atrapado.

\footnotetext{
${ }^{13}$ A continuación el texto de "Los labios de Laura":
}

Entre la hilera de cayenas que bordeaba la piscina y el muro exterior de la cancha de squash, Laura se escondía para enseñarnos a besar. Con un traje de baño floreado de dos piezas nos hacía parar uno a uno. Hernán - cegato y temeroso - se colocaba de primero en la fila; Daniel —enamoradizose reservaba para el final. Algunos - como Ángel- intentaban abrazarla para recibir de golpe un rodillazo que bien sabía asestar en la entrepierna. "Sólo besos" - recalcaba para nuestra sorpresa. Los domingos en la tarde la cola de aspirantes aumentaba y las disputas por el correcto orden de los turnos se hacían frecuentes. Sumidos en la espera, arrancabamos las flores de cayena para estrujarlas lentamente en nuestros puños. Laura llamaba al de turno doblando el índice y entornando los ojos, le cerraba los párpados con la palma de la mano izquierda, le susurraba estáte quieto al oído y proyectaba sus labios hasta tocar los nuestros y abandenar su lengua como pez vivo en la red.

Debe, pues, entenderse que, al quedar desierto el club, termináramos siempre arrojando las sillas de extensión al fondo de la piscina y construyendo castillos submarinos por los que atravesábamos haciendo piruetas y transformando nuestros pulmones en burbujas. Debe, pues, entenderse que, al anochecer, termináramos siempre esperando la reprimenda de Reynaldo el portero, quien nos sacaba de la piscina tirando de nuestras orejas y quien aún debe estar buscando a la escurridiza Laura cada vez que se topa con una mata de cayenas. 
Queremos aquí detenernos y recapitular sobre las relaciones entre la historia y la narración en los tres relatos analizados. En "La nuez" éstas son de separación absoluta: el mundo en el que escribe el narrador está totalmente apartado del mundo del héroe. Por otra parte, en ese cuento no se hace mención alguna a esas relaciones. Pero existen: el mero hecho de escribir sobre el pasado denota implícitamente que éste gravita en torno al narrador. "La lengua" da un paso más allá. Si bien los mundos permanecen separados, se hacen explícitas alusiones a los efectos de la historia sobre la narración: "Desde entonces, quisiéramos creer ... desde entonces quisiéramos borrar ...". En "Los labios de Laura" se plantea un inicio de comunicación entre los dos mundos, mas como una suposición, no como un hecho. En efecto, Reynaldo hace seguramente todavía algo que realizaba en la historia, lo cual nos da la impresión de que la frontera con la narración se rompe.

"En la palma de la mano" (26-27) ${ }^{14}$ nos narra la llegada de Dianela y cómo el héroe se enamora de ella. Su llegada es un cúmulo de hechos puntuales que ve el grupo de muchachos: "La vimos masticando chicle en el trencito, la vimos comiendo pizza ..."15 En el párrafo siguiente, se pasa a la frecuencia iterativa para indicarnos que la presencia de Dianela es reiterada, que ya se ha instalado en una esfera cercana al mundo del héroe. Sabemos así que "hablaba poco", que a veces los miraba fijamente y les soltaba "una risa seca, un jajajá". Luego el relato pasa a la primera persona del singular: el héroe se ha enamorado y esa vivencia no entra en la pandilla, es algo íntimo. El presente histórico subraya el momento en que por primera vez la ve sin la mirada del grupo: "la descubro

\footnotetext{
${ }^{14}$ A continuación el texto de "En la palma de la mano":

Dianela era nueva en el club. Sus ojos, sus labios y la forma hundida de su ombligo también eran cosa nueva para nosotros. La vimos masticando chicle en el trencito del parque, la vimos comiendo pizza en el cine bajo los aullidos de Tarzán, la vimos tomando sol en la piscina con un bikini que todos quisimos desanudar.

Dianela hablaba poco. Se limitaba a mirarnos fijamente de vez en cuando y a soltar una risa seca, un jajajá. Llegaba y paseaba sin móvil fijo mojando sus pies en la grama recién regada. Llegaba y abría sus grandes ojos verdes por entre la cabellera rubia que recogían con dificultad sus hombros. Por un designio que todavía celebro, Dianela coincidió con mi hermana en clases. Una tarde, llegando sediento a casa, la descubro junto a mi hermana haciendo un gran mapa de Venezuela. El cartón mojado - lo adiviné- serían los Llanos; la estopa que estrujaba en sus manos, los Andes. Sumando otras texturas a lo largo de la tarde, las ayudé a terminar el mapa. Intuí una risa seca en Dianela, un jajajá.

En la noche, caminando de rodillas desde mi cuarto, le susurré a mi hermana que estaba enamorado de Dianela, que el amor era una costra dura que crecía en el pecho, que me tenía que ayudar.

A partir de esa confesión, los hechos se ordenan de manera irregular. Sé que la semana siguiente fuimos al cine, sé que mi hermana se sentaría a su lado, sé que la vi pasar con una pizza cuyo queso derretido colgaba entre el plato de cartón y sus dientes, sé que en la pantalla Tarzán luchaba a muerte con un gladiador negro, sé que desde las filas traseras alcancé a pasar la papeleta de mi declaración de mano en mano hasta Dianela, sé que la abrió mientras el gladiador negro caía derrotado en un caldero hirviente, sé que -inesperadamente - la luz se fue y la función tuvo que ser interrumpida a la fuerza.

Entre la maraña de caras que salen del cine, busco ansiosamente el rostro de Dianela. La descubro a lo lejos, no sin cierta vergüenza, y noto que me sonríe. Aún hoy me pregunto cómo habrán resonado en su mente las palabras de la papeleta. Aún hoy espero su respuesta.
}

${ }^{15}$ Cursivas del autor. 
junto a mi hermana haciendo un gran mapa de Venezuela". Las ayuda en su labor intuyendo "una risa seca en Dianela, un jajajá". Por la noche, descubre su enamoramiento a su hermana y al lector: marco e indicios han operado, los extensos antecedentes están dados para pasar al suceso central. Acompasadamente - "Sé que ... sé que ..."- en un tiempo absolutamente singulativo que hace destacar el segundo bloque, se nos narran, intercalando el marco - "Tarzán luchaba ... el gladiador negro caía" - las acciones una tras otra: la ida al cine, la papeleta de declaración que pasa de mano en mano, como la abre Dianela, el corte de luz antes de poder registrar reacción alguna. Podría así concluir el relato, pero sólo tendríamos la causa - la papeleta leída - quedaríamos entonces ante un final totalmente abierto, sonrientes ante una maniobra abortada en el momento de corte de luz. Pero el narrador considera que el relato no se halla acabado y va más allá: salen del cine. El momento en que el héroe busca "ansiosamente el rostro de Dianela" es intensificado con el presente histórico. Al encontrarlo, ve que le sonríe. De cerrar aquí el relator tomaríamos la reacción como signo contundente y nos invadiría un sabor de esperanza: tras la sonrisa vendrá la historia de amor. Pero el acabado continúa para llegar a un punto de cierre en el que inferimos con certeza que Dianela jamás respondió. Se activan entonces los antecedentes. ¿Es por la timidez de quien habla poco, de quien sólo sabe soltar torpes jajajás? ¿Hay detrás de la risa seca más bien cierto desprecio? ¿Qué puede significar la falta de respuesta? Nadie lo sabe: ni el héroe, ni el narrador, ni el lector. Pero las ansias de saber permanecen intactas, se mantienen desde la historia hasta la narración, no constituyen un simple recuerdo, imagen o suposición, por más intensos que éstos puedan ser; son unas ansias incólumes, vivientes en el presente del narrador, que expresa: Aún hoy me pregunto ... Aún hoy espero la respuesta. La apertura al amor no cesa.

En "Bajo los pinos" (28-29) $)^{16}$ encontramos al héroe en La Haya. Imágenes puntuales -patos, lenguado meunière, trineo de madera, grama en alfombras- nos dan el marco de

${ }^{16}$ A continuación el texto de "Bajo los pinos":

Mis recuerdos de La Haya son enumerables: patos que sumergen su cabeza verde en canales casi congelados, un hotel llamado "Europa" donde se me hizo conocer el lenguado meunière, un trineo de madera que fue el pretexto perfecto para no separarme de la nieve.

Al poco tiempo de haber llegado, nos instalamos en Rigolettostraat: una calle de edificaciones nuevas donde traían la grama en alfombras enrolladas y amontonaban las heces de vaca como abono. El polvillo de cemento era nuestro aire y la pintura fresca nuestra fiesta permanente.

La calle comenzó a palpitar con familias que poco a poco fuimos reconociendo. Pieter y su hermano menor me iniciaron en el rugby: una rutina en la que siempre imponían su destreza. Wande me enseñaba sus incisivos amarillos como teclas de piano envejecido. Y, por último, Penny: una norteamericana gordita y pecosa a quien le gustaba llevar la voz cantante.

Nuestro universo se fue poblando de guaridas hechas con desechos de construcción, de escalinatas llenas de cal, de penitencia tan radicales como terminar empujado de boca contra un montículo de abono.

Un extraño círculo se fue tejiendo: Pieter y yo compitiendo en ejercicios varoniles para ganarnos la sonrisa de Wande; Wande indiferente y siempre con una muñeca desgreñada en las manos; Penny sin lograr la atención de los varones y conspirando secretamente contra Wande.

Una tarde de invierno, subiendo ambos en el ascensor de un edificio no inaugurado, Penny oprime un botón rojo y detiene el aparato en el entrepiso. Sin comprender la celada, intento volverlo a poner en marcha cuando Penny se me viene encima y, apretando sus dos frutillas rosadas contra mi 
la ciudad. Comienza a formarse un grupo -Pieter, Wande, Penny y el héroe- - y un universo - guaridas, escalinatas, penitencias. Hasta ahora todo es básicamente descripción por la vía de imágenes, adjetivos y hechos que, más que contar, denotan características. Para el momento en que irrumpe un suceso que precede al central, los antecedentes han dejado claro que los muchachos están viendo aflorar su virilidad, que Wande aún guarda el ancla en la niñez y que la dominante Penny busca desplazarla en las preferencias de los chicos. Todo está listo para borrar el "nosotros" que engloba a la familia en los primeros párrafos y al grupo de amigos en los subsiguientes. Pasamos a una vivencia íntima: el yo se impone. Entramos a un momento de especial intensidad: el presente histórico lo subraya. Penny se abalanza sobre el héroe y lo besa en el ascensor de "un edificio no inaugurado". Este suceso prefigura al central, muestra ya a las claras el arrojo de Penny, deja al heroe oscilante "entre el deseo y el miedo". Se cierran así los antecedentes, todo está maduro para el asalto definitivo: el suceso central. Perseveran la primera persona, el presente histórico y un marco escueto para engranar las acciones. Penny lleva al héroe esta vez a un bosque, lo induce a pedalear muy rápido en una zona resbalosa; caen los dos, ella "se me viene nuevamente encima": la misma causa que en el suceso anterior. Pero ahora la reacción es diferente: el muchacho sí se deja llevar. Se llega entonces a una narración intercalada: ${ }^{17}$ la agitación del momento es recogida por una oscilación entre el pretérito de la historia y el presente de la narración, donde el juramento del narrador parece invocar una memoria precisa para un momento decisivo y confuso: "Juro que su lengua hurgó ...". El suceso central termina y el narrador comenta: "desde ese dia no fuimos los mismos", con lo cual lo ocurrido en la historia queda como hito que se prolonga hasta la narración: Penny y el héroe han aprendido algo que buscaban confusamente y que los transforma para siempre. Pero no ha concluido el acabado: el héroe y Penny, desde la historia, también ratifican la conciencia de un estado de descubrimiento: "supimos que ... por encima de las ramas filosas, un cielo nuevo reverberaba".

"De rodillas" (43-44) $)^{18}$ abre con la descripción de una foto que muestra a los padres del héroe llegando a una recepción de bienvenida a un barco. El padre aparece "serio y

pecho, trata de elaborar sobre mi boca un beso que me supo a agua salobre. Desde ese momento, oscilando entre el deseo y el miedo, opté por no volverme a montar con Penny a solas en un ascensor. Desde la distancia, Penny cierra el círculo con sus manos. Tibiamente, me invita a dar un paseo en bicicleta. Veo patos multicolores, veo niños patinando sobre canales congelados, veo el súbito bosque en el que se ha convertido nuestra ruta. Pedaleando con fuerza y jugueteando con el manubrio, me invita a acelerar el paso. Caigo con facilidad en el juego y terminamos con las bicicletas derrapándose sobre la nieve. Nuestros cuerpos abrigados ruedan sobre la blancura espectral y Penny se me viene nuevamente encima con la precisión de un dardo.

Juro que su lengua hurgó en mi boca hasta que la hizo suya, juro que sus pechos fueron extrañas esponjas que exprimía a mi antojo, juro que su pelvis buscaba acomodo contra la mía, juro que temblamos y que desde ese día no fuimos los mismos.

$\mathrm{Al}$ abrir, detenidos, los ojos, supimos que estábamos bajo unos pinos y que, por encima de las ramas filosas, un cielo nuevo reverberaba.

${ }^{17}$ En la narración intercalada (narration intercalé), "l'histoire et la narration peuvent s'y enchevêtrer de telle sorte que la seconde réagisse sur la première", (Genette 1972: 229).

${ }^{18}$ A continuación el texto de "De rodillas":

Una foto lo preserva. En ella aparece mi madre dándole la mano al capitán del barco con motivo de 
con lentes". Luego se nos da el marco, el barco mismo: piscina, comedor, cubierta. Más tarde se nos detalla el vestido que la madre lucía en la foto: anuncia apenas "la línea divisoria de los senos", posee "dos faldones cortos". El padre muestra una irritación creciente ante el vestido y llega la noche de la recepción. El narrador conjetura el desarrollo de la misma y supone "que habrán regresado cansados de bailar y bebidos ya tarde en la noche". Termina aquí un extenso proceso de acumulación de indicios que nos alista para el suceso central: la violencia del padre que deshace el vestido de la madre. Suceso éste que no ve el héroe, pero que inferimos nosotros por los "tres gritos" del padre que cortan una súplica y por el descubrimiento del "vestido deshecho". Este descubrimiento, ubicado al final, cumple múltiples funciones: cierra el suceso central tras su ocurrencia y rompe el suspenso que sentimos junto con el héroe ansioso de asomar un ojo hacia el otro lado; a la vez que cierra el relato haciendo converger allí todos los indicios y abre nuestra ensonación que, en pos del significado, ronda las pistas de la violencia reprimida, de los celos, y que nos sume en la conmoción.

Deseamos destacar el tiempo utilizado en las últimas líneas: "veo a mi madre ... la veo ...”. No se trata del presente histórico, es algo que va más allá. Se trata más bien de un tiempo que despliega a la historia para la observación, no un tiempo que hace recordar,

una recepción de bienvenida ofrecida por los comandantes de la tripulación. Un poco más atrás, serio y con lentes, mi padre espera turno para recibir los saludos de rigor.

Habíamos zarpado días atrás en el "Irpinia" y atracaríamos en algunos puertos del Caribe antes de cruzar el océano y llegar a Canarias. Varios descubrimientos nos reservaba el trasatlántico: una piscina redonda con agua salada, un comedor especial para niños con sillas y mesas a escala, una cubierta interminable por donde corríamos y la intimidad de los camarotes con sus ventanas ovales y ahumadas.

Mi madre se había hecho el vestido especialmente para el viaje. Había apartado un largo pliego de satén morado que fue delineando con cortes y puntadas. Dos tiras angostas se arqueaban sobre sus hombros anunciando apenas la línea divisoria de los senos y en la parte baja dos faldones cortos pero sucesivos bailaban como faralaos sobre las rodillas. Como remate del atuendo, la foto también muestra dos calabazas castañas de pelo que se sostenían una sobre otra.

Mi padre manifestó cierta incomodidad con el vestido. Primero fueron algunos chistes, luego comentarios al margen y, por último, silencio absoluto. Mi madre se defendía diciendo que era el último grito de la moda, que Jacqueline Kennedy tenía uno igual, que fijate lo que se está usando en Europa.

Los vi salir por la puerta del camarote y la discusión fue muriendo en mis oidos conforme se alejaban por el corredor. La cara con la que me vio mi padre al cerrar la puerta ha debido ser la misma que retrató el fotógrafo: una distancia, un desagrado, una impotencia que lo carcomía.

Nunca supe qué paso en la recepción. Supongo que habrán tomado champaña, supongo que habrán repartido pasapalos exquisitos, supongo que habrán pronunciado el mismo discurso repetido de tantos viajes, supongo que habrán regresado cansados de bailar y bebidos ya tarde en la noche. Lo supongo porque desde el sueño me arrancó la voz sonora de mi padre cortando con tres gritos la súplica que mi madre intentaba elaborar con palabras sueltas.

Devuelto al silencio de la noche, no resistí la tentación de entreabrir la puerta y asomar un ojo hacia el otro lado. Fija como la imagen del primer día, veo a mi madre en ropa interior, la veo caminar de rodillas con el cabello disuelto sobre los hombros, la veo sollozar mientras recoge del suelo los pedazos del vestido desecho. 
sino uno que proyecta una perfecta película del pasado en el presente. Tan perfecta, que es como si el narrador estuviese en la historia.

"Piraguas" (106-107) ${ }^{19}$ relata cómo la madre del héroe "solía aventurarse por la carretera maltrecha que llegaba hasta el puerto de Bachaquero". Tras el recorrido se arriba al universo de las piraguas: un mundo en todo diferente al de los ordenados campos petroleros donde transcurre la mayoría de los cuentos del corpus. Allí se apelmazan "pesados lanchones" que traen de todo en "sus vientres abiertos". Allí se agrupan "hombres achinados y gordos ... bajo el dictado de una ley desconocida" que, entre otras cosas, prescribe no toparse nunca con la mirada de ellos. De esta manera, a través de acciones iterativas y enumeración de detalles, quedan acumulados suficientes indicios que revelan lo ajeno que le resulta ese medio al héroe. Ya puede desplegarse entonces el suceso central, ya puede el niño asomarse para que "el ogro de barriga hinchada, franela a reventar, ombligo saliente y ojos verde esmeralda" lo atraviese con la mirada.

El narrador dispone el relato de manera tal que la causa y no la reacción es la que aparece justo en las últimas palabras: "aún se asoma tras la ventanilla trasera del carro detenido". De esta manera retiene al máximo la infracción a la ley desconocida y la utiliza como punto de cierre del relato, desde donde se abren las posibilidades de significación: el mundo es extraño, sí, pero fascinante, por ello es que, aunque sea "ahumando el vidrio", aunque se tenga "el aliento entrecortado del miedo", debemos asomarnos. Esa resolución se perpetúa hasta el presente, el niño "aún se asoma". Se diría que el chico sale de la historia e irrumpe al mundo de la narración. Sin embargo, nuestro relato no posee ningún ribete fantástico. ¿Qué ocurre entonces?: una ilusión de metalepsis narrativa ${ }^{20}$ cuya función

${ }^{19}$ A continuación el texto de "Piraguas":

Mi madre solía aventurarse por la carretera maltrecha que llegaba hasta el puerto de Bachaquero. El carro avanzaba dando tropezones, cayendo religiosamente en los huecos anegados de lluvia y exponiendo el parabrisas a los chorros de agua marrón que salían expelidos de los charcos.

Llegar al puerto era presenciar el universo de lo que ella llamaba "las piraguas": pesados lanchones que atracaban apelmazados por docenas trayendo en sus vientres abiertos una verdadera cornucopia de todo lo que entregaban aquellas tierras: plátanos verdes en racimos, curvinas hinchadas y frescas, queso blanco en latones, lechosas de Casigua, café andino en granos, reses enteras de Santa Bárbara, frascos violáceos de hicacos.

El temor por la ruta sinuosa - una carretera cada día más carcomida por la maleza — bien valía el riesgo: un verdadero inventario, un verdadero canto a la agricultura de la zona tórrida, hacía irrupción ante nuestros ojos brotados como un idéntico reflejo.

Para colmo, emulando la lenta órbita del sol en el cénit, un tropel de hombres achinados y sordos rumiaba entre el muelle y las barcazas bajo el dictado de una ley desconocida: nada importaba más que la evolución dilatada de las cosas, nada importaba más que extraviar la vista en todo lo que no les era afin. De ahí que el ogro de barriga hinchada, franela a reventar, ombligo saliente y ojos verde esmeralda, mire fijamente al niño que, ahumando el vidrio bajo el aliento entrecortado del miedo, aún se asoma tras la ventanilla trasera del carro detenido.

${ }^{20}$ La metalepsia narrativa (métalepse narrative) consiste en "toute intrusion du narrateur ou du narrataire extradiégétique dans l'univers diégétique (ou de personnages diégétiques dans un univers métadiégétique, etc.) ou inversement" (Genette 1972: 244). Nos encontramos en el "inversement": una intrusión - aquí ilusoria- de lo diegético en el mundo del narrador extradiegético. En todo caso, cualquiera que sea la forma que adopte, la verdadera metalepsis narrativa es una transgresión de una frontera sagrada entre dos mundos: uno en donde se cuenta y otro que es contado. 
es dar fuerza y sentido pleno al final: la fascinación temerosa del niño ante la extrañez del mundo todavía está presente en el narrador.

\section{OBSERVACIONES FINALES}

Retomando la definición básica de Friedman, podemos sostener que los textos estudiados son ejemplos de prosa corta de ficción, con una manera particular de ser narrativos. Nos explicamos. Contienen todos nuestros textos un suceso central, crucial para el sentido del relato. Ello les da sin duda la condición de cuentos, pero el tono del conjunto es más bien lírico. En efecto, más que encadenar hechos, se diría que el narrador persigue plasmar una emoción valiéndose de una historia. Así, contar la historia no es el fin, sólo el medio para objetivar un estado. Entendemos ahora la "paradoja" de la narrativa de López Ortega: se trata ciertamente de historias — cambios de estado- pero contadas con el objetivo de fijar un estado de deseo, destierro, excitación, amor, descubrimiento, conmoción, fascinación temerosa. Son cuentos, claro, pero cuentos líricos. ${ }^{21}$

¿Cómo opera este cuento lírico? Lo hace básicamente en torno a tres funciones globales, que existen independientemente de que se constituyen en tres bloques separados. Una, con mucho la más extensa, crea el escenario de sentido en el que se insertará el suceso central. Aunque puede utilizar elementos que, considerados aisladamente, pasen por narrativos, su globalidad es descriptiva. Otra, bastante breve, corresponde al suceso central. Puede emplear algunos elementos más bien descriptivos, pero su globalidad es absolutamente narrativa. Otra, igualmente corta, ligada siempre al suceso central, crea las condiciones para que el lector tenga la sensación de un final adecuado.

Vemos así que las tres funciones están vinculadas al suceso central. Podríamos decir que una le da el telón de fondo y que la otra lo comenta. Mucho gira pues alrededor del núcleo narrativo y, sin embargo, el tono lírico persiste. Claro que en ello influye la extensión de las funciones no narrativas, pero pensamos que lo decisivo en este aspecto es el punto de cierre. En efecto, por ser este punto, desencadente básico del sentido, el que liga todo el relato a una emoción, al estado que ella provoca, experimentamos la preponderancia de lo lírico como tono, aunque todo gravite en torno al suceso central. De nuevo, un cuento; de nuevo, lírico. Y, quizás como nunca antes en su obra, una armonía entre dos fuerzas que luchan en López Ortega: el placer de contar y el afán de consignar un sentir.

Por último, una referencia a las relaciones entre historia y narración. A lo largo de nuestro corpus hemos visto cómo, en forma creciente, esos dos mundos se van acercando, cómo la frontera entre ambos se va desdibujando para potenciar la fuerza del pasado en el presente. Sin embargo, en "Piraguas", nos damos cuenta de que hay algo más: la aspiración a una imposible lucidez. Nos explicamos.

Quien recuerda y cuenta, como el narrador de nuestro corpus, ve todo después del final. Sabe que ya no se encuentra en la historia, que su tiempo es otro. Ello le da el dominio total de un universo concluido donde cada elemento se encuentra definitivamente en su lugar, le permite elegir los episodios más significativos de una comarca que ya

${ }^{21}$ Eileen Baldeswhiler, citada en la bibliografia, desarrolla una caracterización del cuento lírico al cual opone el cuento épico. 
conoce y saber perfectamente hacia dónde se dirige: hacia el punto de cierre que abrirá un significado que era indiscernible en el tiempo de la historia y que él ahora, en el tiempo de la narración, poseedor de la perspectiva necesaria, detenta. Pero nuestro narrador no se da por satisfecho con lo anterior. Desearía también romper con el final como algo que clausura y relega hechos a una dimensión que dejó de existir; desearía traer el pasado al presente, la historia a la narración. En fin, desearía el narrador la lucidez absoluta: ver con perspectiva un tiempo vuelto actual, saber el sentido del asomo a la ventanilla mientras se coloca tras ella por primera vez.

\section{BIBLIOGRAFÍA CITADA Y REFERENCIAS}

Baldeswhiler, Eileen. "The Lyric Short Story: The Sketch of a History". Short Story Theories. Ohio: Ohio University Press, 1977.

Dijk, Teun Van. La ciencia del texto. Barcelona: Ediciones Paidós, 1989.

Friedman, Norman. "Recent Short Story Theories: Problems in Definition". Short Story Theory at a Crossroads. Baton Rouge: Louisiana State University Press, 1989.

Genette, Gérard. Figures III. París: Éditions du Seuil, 1972. Nouveau Discours du récit. París: Éditions du Seuil, 1988.

Gerlach, John. Toward the End: Closure and Structure in the American Short Story. Tuscaloosa: The University of Alabama Press, 1985.

Hamon, Philippe. "Clausules”. Poétique, 24. París, 1975, 495-526.

Kermode, Frank. The Sense of an Ending. Oxford: Oxford University Press, 1967.

Lohafer, Susan. Coming to Terms with the Short Story. Baton Rouge: Louisiana State University Press, 1983.

López Ortega, Antonio. "Larvarios". Cuerpo plural. Caracas: Ediciones La Gaveta, 1978.

"Armar los cuerpos". Voces nuevas. Caracas: Centro de Estudios Latinoamericanos Rómulo Gallegos, 1982. Cartas de Relación. Caracas: Fundarte, 1982. Calendario. Caracas: Monte Ávila Editores, 1990. Naturalezas menores. Caracas: Alfadil Ediciones, 1991.

Meneses, Guillermo. El cuento venezolano. Buenos Aires: Editorial Universitaria de Buenos Aires, 1966.

Poe, Edgar Allan. "Review of Twice-Told Tales". Short Story Theories. Ohio: Ohio University Press, 1976. Originalmente publicado en 1842.

Rionter, David H. Fable's End. Chicago: The University of Chicago Press, 1974.

Torgovnick, Marianna. Closure in the Novel. Princeton: Princeton University Press, 1981.

Wright, Austin. "On Defining the Short Story: The Genre Question". Short Story Theory at a Crossroads. Baton Rouge: Louisiana State University, 1989. 